\title{
Identification of hydrophobic proteins FepD and FepG of the Escherichia coli ferrienterobactin permease
}

\author{
Sara S. Chenault and Charles F. Earhart* \\ Department of Microbiology, University of Texas at Austin, Austin, Texas 78712-1095, USA
}

(Received 16 March 1992; revised 24 June 1992; accepted 10 July 1992)

\begin{abstract}
In Escherichia coli, iron assimilation by means of the siderophore enterobactin requires two hydrophobic cytoplasmic membrane proteins, FepD and FepG, which are essential components of a binding-protein-dependent transport system. Such components are typically difficult to detect. Here we report observation of the $f e p D$ and fep $G$ gene products in polyacrylamide gels; they appeared as diffuse bands at positions consistent with smaller sizes than those predicted by sequence analysis. Translational coupling was suggested by the lack of a detectable product from the $f e p G$ message in the absence of translation of the upstream $f e p D$ message. The orientation of FepD/FepG in the membrane was predicted based on their similarities in sequence and hydrophobicity to FhuB.
\end{abstract}

\section{Introduction}

Escherichia coli and other enteric organisms are able to thrive under conditions of low iron availability by the use of high affinity iron chelators (siderophores) either endogenously synthesized or fortuitously present. The siderophore enterobactin (Ent) is made in $E$. coli by biosynthetic enzymes encoded in the Ent cluster of genes. This cluster also contains genes for the transport of $\mathrm{Fe}$ (III)-Ent and for the intracellular release of the iron (Earhart, 1987). These genes are derepressed when the intracellular level of iron is low, this regulation being accomplished, at least partially, by the fur product which is an aporepressor (Hantke, 1981; Bagg \& Neilands, 1987).

Ferri-Ent is transported into cells by means of a periplasmic permease, one of the iron/B12 subset (Shea \& McIntosh, 1991) of binding protein-dependent transport systems, whose members require an outer membrane receptor and the tonB function (Postle, 1990). In addition to the FepA protein in the outer membrane (Neilands, 1982), the system requires FepB, the periplasmic binding protein (Pierce et al., 1983; Pierce \& Earhart, 1986; Elkins \& Earhart, 1989), FepC, an innermembrane-associated protein (Pierce \& Earhart, 1986; Ozenberger et al., 1987) with an apparent ATP-binding site (Shea \& McIntosh, 1991), and two hydrophobic proteins recently sequenced and characterized, designated FepD and FepG (Chenault \& Earhart, 1991; Shea \& McIntosh, 1991). The fepD and $f e p G$ genes are located

* Author for correspondence. Tel. (512) 4711561 ; fax (512) 4717088. just upstream of $f e p C$ and are transcribed with it as an operon in the direction fepDGC. Although the product of the distal gene $f e p C$ has been seen repeatedly, earlier attempts to visualize proteins encoded from the fepDG sequence have been unsuccessful (Pierce \& Earhart, 1986; Ozenberger et al., 1987; Shea \& McIntosh, 1991).

It has been assumed previously that periplasmic permeases require the hydrophobic inner membrane components in very small amounts and that this explained the difficulties in identifying and studying these proteins. It now seems likely that each membrane transport complex contains one to four proteins such that the complex includes two hydrophobic integral membrane domains and two associated hydrophilic ATPbinding domains (Higgins et al., 1990a, b). This has been directly demonstrated for the histidine permease by means of chemical cross-linking and immunoprecipitation (Kerppola et al., 1991). If the same stoichiometry applies in the case of the comparable ferri-Ent transport system, this would predict that two molecules of FepC plus one each of FepD and FepG constitute the membrane transport complex. It would therefore seem likely that the difficulties in visualizing these proteins have been partially technical; for example, hydrophobic proteins are often precipitated by boiling in SDS (Beyreuther et al., 1980; Ito, 1984; Koster \& Braun, 1986), a commonly used procedure for preparing samples for acrylamide gels. In this paper the expression and membrane localization of FepD and FepG were studied using plasmids with a T7 RNA polymerase start site (Tabor \& Richardson, 1985). 


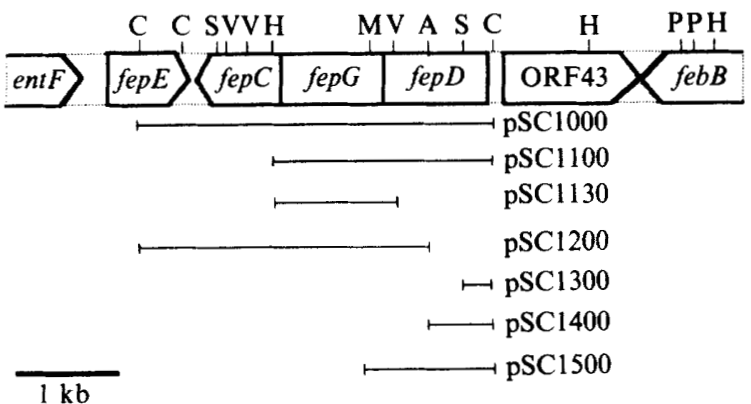

Fig. 1. Partial map of $E$. coli ferri-Ent transport genes. Insert DNA fragments from plasmids are drawn below. Restriction site abbreviations are: A, AccI; C, ClaI $; \mathrm{H}, H p a \mathrm{I} ; \mathrm{M}, M l u \mathrm{I} ; \mathrm{S}, S t u \mathrm{I} ; \mathrm{V}, E c o \mathrm{RV}$.

\section{Methods}

Strains and plasmids. Protein expression experiments were done with strain K38/pGP1-2 (Tabor \& Richardson, 1985) carrying plasmids with inserts shown in Fig. 1. All plasmids were derivatives of pCEM3Z (Promega Biotec) which carries the gene for $\beta$-lactamase in a position to be transcribed in the incorrect direction by T7 RNA polymerase. Plasmids are described more fully in Chenault \& Earhart, 1991.

Iron-deficient medium. LB (Nagel de Zwaig \& Luria, 1967) was made iron-deficient by adding $0.2 \mathrm{~mm}-2,2^{\prime}$ dipyridyl from Sigma.

Protein expression and labelling. Proteins were labelled by a previously described modification (Chenault \& Earhart, 1991) of the method of Tabor \& Richardson (1985). Cells were maintained in an iron-deficient medium to prevent Fur-binding which might interfere with transcription even by the T7 RNA polymerase. Protein samples were not boiled but were solubilized at $37^{\circ} \mathrm{C}$ for $5 \mathrm{~min}$ in sample buffer (Koster \& Braun, 1986, 1989). Polyacrylamide gel electrophoresis was carried out as described previously (Pierce \& Earhart, 1986). Molecular mass standards were purchased from BRL and were as follows: lysozyme, $14.3 \mathrm{kDa} ; \beta$-lactoglobulin, $18.4 \mathrm{kDa}$; carbonic anhydrase, $29 \mathrm{kDa}$; ovalbumin, $43 \mathrm{kDa}$; bovine serum albumin, $68 \mathrm{kDa}$; phosphorylase b, $97.4 \mathrm{kDa}$; myosin (H-chain), $200 \mathrm{kDa}$.

\section{Results and Discussion}

\section{Identification of proteins FepD and FepG}

Expression of proteins from plasmids (Fig. 1) carrying various regions of the Ent transport gene sequence is shown in Fig. 2. In the presence of rifampicin (lanes 3, 6, $9,12,14$ and 15) there was minimal incorporation of label into chromosomally-encoded proteins; $\beta$-lactamase is not present as its gene was transcribed in the incorrect direction. The dark band running at about $30 \mathrm{kDa}$ in lanes 9 and 15 has been previously identified in minicell preparations as FepC (Pierce \& Earhart, 1986; Ozenberger et al., 1987; Shea \& McIntosh, 1991). Since $\mathrm{pSC} 1100$ carries only two genes, fepD and fepG, the two diffuse bands ( $24 \mathrm{kDa}$ and $26 \mathrm{kDa}$ ) in lane 12 , as well as the same bands in lane 9 , were tentatively identified as the products of these. Expression of the fep $D$ gene alone from pSC1500 (Fig. 3, lane 6), identified the $26 \mathrm{kDa}$ band as FepG and the $24 \mathrm{kDa}$ band as FepD. In the gel shown, the FepD protein for unexplained reasons ran as a doublet. Both FepD and FepG appear to be smaller than the sizes predicted by sequence analysis: $33805 \mathrm{Da}$ for FepD (Chenault \& Earhart, 1991; Shea \& McIntosh, 1991) and 34997 Da for FepG (Shea \& McIntosh, 1991). When loaded onto a $15 \%(\mathrm{w} / \mathrm{v})$ polyacrylamide gel the apparent sizes of the proteins were $28 \mathrm{kDa}$ and $30 \mathrm{kDa}$, respectively (not shown). When samples were treated at $95^{\circ} \mathrm{C}$ for $5 \mathrm{~min}$, radioactivity was concentrated in the wells of the gel; FepD and FepG bands were absent (not shown).

It is typical of very hydrophobic proteins that they are precipitated by boiling in SDS and that they are found after gel electrophoresis in diffuse bands at positions not consistent with their actual size (Beyreuther et al., 1980; Ito, 1984; Dassa \& Hofnung, 1985; Koster \& Braun, 1986). The $70 \mathrm{kDa}$ FhuB protein (Koster \& Braun, 1989), which has significant sequence homologies with FepD and FepG (Chenault \& Earhart, 1991 ; Shea \& McIntosh, 1991), was found on gels at size positions ranging from 41000 to $76000 \mathrm{Da}$ as acrylamide concentration and cross-linking were increased (Koster \& Braun, 1986). Other similar proteins, $\mathrm{FecC}$ and $\mathrm{FecD}$, which transport ferric dicitrate, were also seen in $15 \%$ polyacrylamide gels at anomalous postions ( $32 \mathrm{kDa}$ rather than $35.4 \mathrm{kDa}$ for $\mathrm{FecC} ; 29.5 \mathrm{kDa}$ rather than $34.1 \mathrm{kDa}$ for $\mathrm{FecD}$; Staudenmaier et al., 1989).

\section{Possible translational coupling of FepD and FepG}

Expression of plasmids carrying the complete fepG sequence but lacking the start site and $5^{\prime}$ end of the fepD gene failed to produce detectable amounts of FepG (Fig. 2 , lanes 14 and 15). This does not appear to be a failure of transcription, as the product of $f e p C$, distal to $f e p G$ on the same operon (Chenault \& Earhart, 1991; Shea \& McIntosh, 1991) was clearly seen in lane 15 (pSC1200, $\mathrm{FepG}^{+} \mathrm{FepC}^{+}$). The fepG start codon is overlapped by the $f e p D$ stop signal (ATGA). It would not, therefore, be surprising if synthesis of FepG is closely coupled to that of FepD, causing the production of the downstream gene product to depend upon translation of the proximal $f e p D$ message. Predicted secondary structure (Fig. 4) could make this sequence and the preceding ribosome-binding site inaccessible unless opened up by the ribosome(s) translating the promoter-proximal fepD message. Obligatory translational coupling often seems to be mediated by the presence of secondary structure in the vicinity of the Shine-Dalgarno sequence and start codon of the distal gene (Hall et al., 1982; Gold, 1988). 


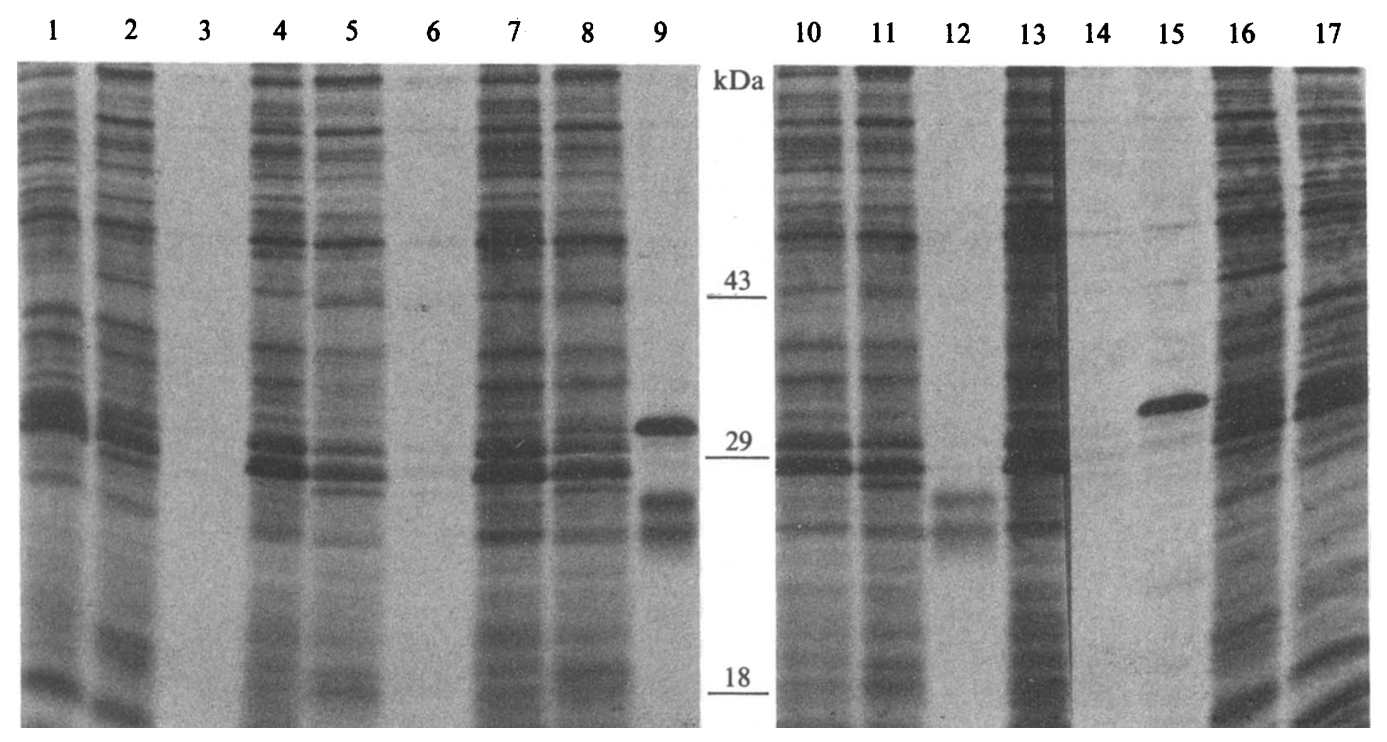

Fig. 2. Autoradiogram of proteins synthesized in cells harbouring $f e p$-bearing plasmids and resolved in a $10 \%$ (w/v) polyacrylamide gel. Positions of molecular mass standards are shown. Plasmids expressed are pSC1300, lanes 1-3; pSC1400, lanes 4-6; pSC1000, lanes 7-9; pSC1100, lanes 10-12; pSC1130, lanes 13-14; pSC1200, lanes 15-17. Conditions were as follows: lanes 1, 4, 7, 10, 13 and 17, no rifampicin, T7 polymerase not induced; lanes $2,5,8,11$ and 16 , no rifampicin, T7 polymerase induced; lanes $3,6,9,12,14$ and 15 , $400 \mu \mathrm{g}$ rifampicin $\mathrm{ml}^{-1}$, $\mathrm{T} 7$ polymerase induced.

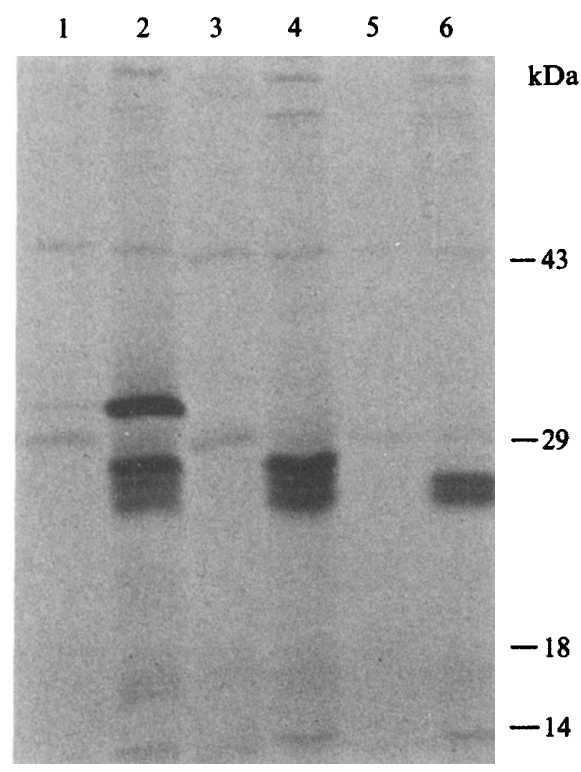

Fig. 3. Autoradiogram of a $10 \%(w / v)$ polyacrylamide gel after electrophoretic separation of proteins from cells bearing fep genes. Plasmids expressed: lanes 1 and 2,pSC1000; lanes 3 and 4,pSC1100; lanes 5 and 6,pSC1500. Conditions: lanes 1,3 and 5, 400 $\mu \mathrm{g}$ rifampicin $\mathrm{ml}^{-1}, \mathrm{~T} 7$ polymerase not induced; lanes 2,4 and $6,400 \mu \mathrm{g}$ rifampicin $\mathrm{ml}^{-1}, \mathrm{~T} 7$ polymerase induced.

\section{FepG, FepD and FepC, members of a permease family}

The Ent permease proteins are members of the superfamily of 'Traffic ATPases' (Ames et al., 1990) or ABCtransporters (Higgins et al., 1990 a,b) and are particularly

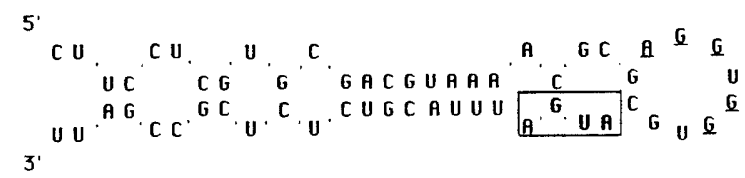

Fig. 4. Possible stem and loop structure involving the fep $G$ translation start site. Underlined bases are probably included in the ribosomebinding site; overlapping start and stop ( $f e p D$ ) codons are within the box.

closely related to systems which transport ferric complexes. At this time there is no specific data available about interaction among the membrane-associated components FepD, FepG and FepC; however, working hypotheses concerning these interactions appear to be compatible with the growing body of information about the larger family.

\section{Tertiary structure and membrane position}

By analogy with the FhuB protein, it is very likely that the carboxy-terminus of FepD is closely associated with the amino portion of FepG. The FhuB sequence (Koster \& Braun, 1986) has internal homology between the two halves (Koster \& Braun, 1989; Staudenmaier et al., 1989) and is highly homologous to the combined sequences of FepD (Chenault \& Earhart, 1991; Shea \& McIntosh, 1991) and FepG (Shea \& McIntosh, 1991) with a short polar bridging sequence. Amino acid residues 1-328 of 


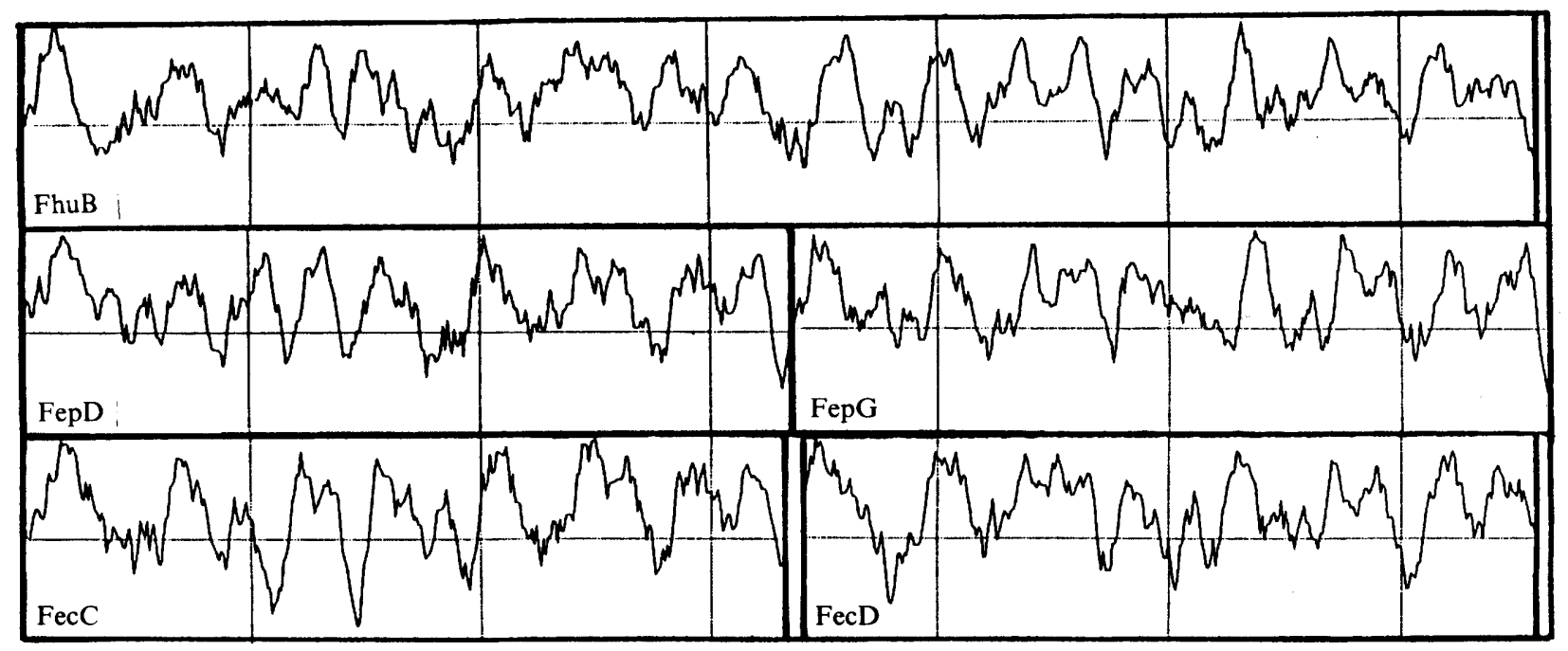

Fig. 5. Hydropathy plots of proteins FhuB (Koster \& Braun, 1986), FepD (Chenault \& Earhart, 1991; Shea \& McIntosh, 1991), FepG (Shea \& McIntosh, 1991), FecC and FecD (Staudenmaier et al., 1989) aligned to demonstrate similarities. Vertical sections represent 100 amino acid residues. Residues located above the horizontal line in each graph are hydrophobic.

FhuB are $25 \%$ homologous to residues $334-659$ (Koster \& Braun, 1989). If the two halves of the protein are positioned in the membrane similarly to one another, both ends of the molecule would be on the same side. Since the polar bridging sequence should not cross the membrane, FhuB sequences homologous to the FepD carboxy-terminus and the FepG amino-terminus would necessarily be positioned close together on either the cytoplasmic or periplasmic side. Hydropathy plots (Fig. 5) are very similar for FhuB and FepD/FepG as well as for $\mathrm{FecC} / \mathrm{FecD}$ of the ferri-dicitrate permease. It seems reasonable to assume that the FepDG and FecCD heterodimers have tertiary structure and membrane position comparable to that of FhuB. The homology between the two halves of FhuB leads to the conclusion that the ends of the molecule lie on the same side of the membrane (Koster \& Braun, 1989). It then follows that the two ends of both FepD and FepG are on the same side of their respective molecules, each protein crossing the membrane an even number of times.

If the ferri-Ent transport complex has the stoichiometry of the histidine system (Kerppola et al., 1991), a $1: 1$ ratio of FepD to FepG would be required; close translational coupling would produce this ratio as well as positioning the second translation product for immediate and correct association with the first. One further step in the histidine analogy predicts two FepC proteins to interact with the FepD-FepG heterodimer. This, of course, would imply translation starts that are independent of translation of the upstream FepG; these do seem to occur despite overlapping stop and start codons. Since submitting this manuscript we discovered the paper by
Pearce et al. (1992), describing the membrane topology of integral membrane proteins OppB and OppC. Each spans the membrane six times with both termini on the cytoplasmic face. These results are consistent with those which we have predicted for FepG and FepD.

The authors wish to thank Dr Stanley Tabor for strain K38 and Edward Marcotte for assistance with protein expression experiments. This work was supported by a biomedical research support grant from the University of Texas at Austin and by grant BCS 9013007 from the National Science Foundation.

\section{References}

Ames, G. F.-L., Mimura, C. S. \& Shyamala, V. (1990). Bacterial periplasmic permeases belong to a family of transport proteins operating from Escherichia coli to human: Traffic ATPases. FEMS Microbiology Reviews 75, 429-446.

BAGG, A. \& NeILANDS, J. B. (1987). Molecular mechanism of regulation of siderophore-mediated iron asimilation. Microbiological Reviews 51, 509-518.

Beyreuther, K., Bieseler, B., Ehring, R., Griesser, H.-W., Mieschendah, M., Muller-Hill, B. \& Triesch, I. (1980). Investigation of structure and function of lactose permease of Escherichia coli. Biochemical Society Transactions 8, 675-676.

Chenault, S. S. \& Earhart, C. F. (1991). Organization of genes encoding membrane proteins of the Escherichia coli ferrienterobactin permease. Molecular Microbiology 5, 1405-1413.

Dassa, E. \& Hofnung. M. (1985). Sequence of gene malG in E. coli K12: homologies between integral membrane components from binding protein-dependent transport systems. EMBO Journal 4, 2287-2293.

EARHART, C. F. (1987). Ferrienterobactin transport in Escherichia coli. In Iron Transport in Microbes, Plants and Animals, pp. 67-84. Edited by G. Winkelman, D. van der Helm \& J. B. Neilands. Weinheim: $\mathrm{VCH}$.

ElkiNs, M. F. \& Earhart, C. F. (1989). Nucleotide sequence and regulation of Escherichia coli gene for ferrienterobactin transport protein FepB. Journal of Bacteriology 171, 5443-5451. 
GoLD, L. (1988). Posttranscriptional regulatory mechanisms in Escherichia coli. Annual Review of Biochemistry 57, 199-233.

Hall, M. N., Gabay, J., Debarbouille, M. \& SchwartZ, M. (1982). A role for mRNA secondary structure in the control of translation initiation. Nature, London 295, 616-618.

HANTKE, K. (1981). Regulation of ferric iron transport in Escherichia coli K12: isolation of a constitutive mutant. Molecular and General Genetics 182, 288-292.

Higgins, C. F., Hyde, S. C., Minnack, M. M., Gileadi, U., Gill, D. R. \& GallaGheR, M. P. (1990a). Binding-protein-dependent transport systems. Journal of Bioenergetics and Biomembranes 22, 571-592.

Higgins, C. F., Gallagher, M. P., Hyde, S. C., Mimmack, M. L. \& Pearce, S. R. (1990 $b$ ). Periplasmic binding protein-dependent transport systems: the membrane-associated components. Philosophical Transactions of the Royal Society of London B 326, 353-365.

ITo, $K$. (1984). Identification of the $\sec Y(\mathrm{prlA})$ gene product involved in protein export in Escherichia coli. Molecular and General Genetics 197, 204-208.

Kerppola, R. E., Shyamala, V. K., Klebba, P. \& Ames, G. F.-L. (1991). The membrane-bound proteins of periplasmic permeases form a complex. Identification of the histidine permease HisQMP complex. Journal of Biological Chemistry 264, 9857-9865.

KOSTER, W. \& BRAUN, V. (1986). Iron hydroxamate transport of Escherichia coli: nucleotide sequence of the $f h u B$ gene and identification of the protein. Molecuiar and General Genetics 204, 435-442.

Koster, W., \& Braun, V. (1989). Iron-hydroxamate transport into Escherichia coli K12: localization of FhuD in the periplasm and of FhuB in the cytoplasmic membrane. Molecular and General Genetics 217, 233-239.

NAGEL DE ZWAiG, R. \& LURIA S. E. (1967). Genetics and physiology of colicin-tolerant mutants of Escherichia coli. Journal of Bacteriology 94, 1112-1123.
Neilands, J. B. (1982). Microbial envelope proteins related to iron. Annual Review of Microbiology 36, 285-309.

Ozenberger, B. A., NaHLIK, M. S. \& McIntosh, M. A. (1987). Genetic organization of multiple fep genes encoding ferric enterobactin transport functions in Escherichia coli. Journal of Bacteriology 169, 3638-3646.

Pearce, S. R., Mimmack, M. L., Gallagher, M. P., Gileadi, U., Hyde, S. C. \& HigGins, C. F. (1992) Membrane topology of the integral membrane components, OppB and OppC, of the oligopeptide permease of Salmonella typhimurium. Molecular Microbiology 6, 47-57.

Pierce, J. R. \& Earhart, C. F. (1986). Escherichia coli K 12 envelope proteins specifically required for ferrienterobactin uptake. Journal of Bacteriology 166, 930-936.

Pierce, J. R., Pickett, C. L. \& Earhart, C. F. (1983). Two fep genes are required for ferrienterochelin uptake in Escherichia coli K-12. Journal of Bacteriology 155, 330-336.

PostLe, K. (1990). TonB and the Gram-negative dilemma. Molecular Microbiology 4, 2019-2025.

SheA, C. M. \& McIntosh, M. A. (1991). Nucleotide sequence and genetic organization of the ferric enterobactin transport system: homology to other periplasmic binding protein-dependent systems in Escherichia coli. Molecular Microbiology 5, 1415-1428.

Staudenmaier, H., Van Hove, B., Yaraghi, A. \& Braun, V. (1989). Nucleotide sequences of the fecBCDE genes and locations of the proteins suggest a periplasmic-binding-protein-dependent transport mechanism for iron(III) dicitrate in Escherichia coli. Journal of Bacteriology 171, 2626-2633.

TABOR, S. \& RiCHARDSON, C. C. (1985). A bacteriophage T7 RNA polymerase/promoter system for controlled exclusive expression of specific genes. Proceedings of the National Academy of Sciences of the United States of America 82, 1074-1078. 